\title{
Characterisation of CyClists' Willingness to PaY for Green INITIATIVES AT AFriCA's LARgeSt CyCle TOUR
}

\author{
Melville Saayman \\ Tourism Research in Economic Environs and Society (TREES), North-West University \\ Waldo Krugell and Andrea Saayman \\ School of Economics, North-West University \\ Accepted: April 2016
}

The Cape Argus Pick $n$ Pay Cycle Tour is a major event on the road cycling calendar. The majority of cyclists travel significant distances and participation produces a substantial carbon footprint. This paper examines participants' willingness to pay to offset their carbon footprint. The purpose of this paper is to make a contribution to the literature by linking willingness to pay to attitudes towards or beliefs (green views) about the initiatives in place, to ensure a greener cycle tour. Factor analysis is used to identify different types of cyclists, based on their green views: those with green money, those who prefer green products and the "re-cyclers". The results of the regression analysis reveal that socio-demographic variables and the right attitude towards the environment are significant predictors of stated willingness to pay for climate change mitigation.

Key words: environmental sustainability, sports events, willingness to pay, climate change mitigation

JEL: D01, L83, Q51, 53

\section{Introduction}

Today more than ever, tourism development has to be environmentally sustainable. Tourists are starting to demand "green" facilities and experiences and are frequently willing to pay for these (Saayman, Krugell \& Saayman, 2016). In response, service providers are keen to promote their sustainability credentials. This paper aims to make a contribution to the literature on estimating the impact of green views on willingness to pay (WTP) at a major sports event in South Africa - the Cape Argus Pick $n$ Pay Cycle Tour (hereafter referred to as the cycle tour) in Cape Town, South Africa. This event is the biggest cycle tour in Africa. Most of the participants travel significant distances to participate and spend some days in and around Cape Town as tourists. Based on the characteristics of the cyclists, an online carbon calculator shows that the carbon footprint of the average participant is approximately $150 \mathrm{~kg}$ of $\mathrm{CO}_{2}$, for the event. This amount could be offset by planting 1.2 trees (Food and Trees for Africa, 2013).

A sizable body of international academic literature that examines different aspects of the environment and tourism exists. The greatest challenge is climate change, and four categories of studies investigating the links between tourism and climate change (Fisher, 2007) are identified: i) the impact of tourism on climate change; ii) the impact of climate change on tourism; iii) adaptation to climate change, and iv) mitigation of climate change. Willingness-to-pay (WTP) for actions that mitigate climate change is included in the above categories. Here, the scope examined ranges from global climate change, e.g. studies that focus on air travellers' WTP for carbon offsets (Brouwer, Brander \& Van Beukering, 2008), to different sustainability or green efforts, such as tourists' willingness to contribute to funds for the management and conservation of a particular natural resource (Casey, Brown \& Schmann, 2010) and to people's attitudes and motives (Widegren, 1998; Stern, Dietz \& Kalof, 1993; Halkos \& Matsiori, 2015). This paper is part of this second area of focus and applies the question of the carbon footprint and green initiatives to a sports event. 
The paper is structured as follows: Section 2 provides a review of willingness-to-pay studies linked to the mitigation of climate change. Section 3 provides a description of the data collected in the survey. Section 4 presents a principle component analysis of the cyclists' green views and a regression model of the predictors of WTP, and the final section provides the conclusions and recommendations.

\section{Willingness-to-pay}

This brief review of the literature consists of three parts: the first suggests reasons why it is difficult to persuade people to pay for the environmental impact of their activities; the second discusses the different elements of the Contingent Valuation method frequently used to gauge WTP; and the third reviews the earlier analysis of who would be willing to pay.

\subsection{Why should they pay?}

The earth's atmosphere and the climate that sustains life as we know it are characterised as a common good (Van Tonder, 2013). They are not owned by anyone and are used by everyone. In a mixed economy, our production and consumption activities are undertaken via the market and the scarcity of land, labour and capital are accounted for by their prices. The goods and services that are produced and consumed are sold and bought at different prices via the market. However, these activities are often accompanied by pollution. The cost of this pollution is not paid for by private companies or individuals, but is a social cost borne by society. In the long run our production, consumption and pollution endanger natural habitats and change the climate, which in turn has an impact on food production and human settlements and creates costs in terms of droughts, floods and other climatic disasters. If these social costs could be included in the price of our private production and consumption activities we would have an incentive to produce and consume less, or to employ cleaner methods of doing so, but this does not occur. The market fails to account for the social costs, since no one owns their share of a sustainable environment to sell to polluters and in consequence no market or price exists. The result is the "tragedy of the commons", whereby the common pool resource is depleted (Black, Calitz \& Steenkamp, 2010). Since the consumers are not paying for it, society is deriving utility from the environment at a rate that is unsustainable.

It may be asked why we do not all cooperate to make some payment to help offset our impact on the environment? Such a user-pays approach would have to be limited to voluntary contributions for a number of reasons. Since no one owns the environment, it is not clear to whom payments should be made when one pollutes. In the case of voluntary purchases of carbon credits, the payments could go towards private or not-for-profit forestry programmes that capture carbon. For payment to occur on a larger scale, governments need to create carbon markets. They would then be permitted to sell pollution rights if they are able to set carbon caps, measure pollution levels, link these to the polluters and fine those that do not cooperate. Pollution rights or carbon credits could then be bought and sold to approximate a market price for the external cost of the pollution. Along with the creation of a carbon market, government might also levy carbon taxes on polluters and in that way "price" the cost of pollution (Black et al., 2010).

Fundamentally, however, cooperation is likely to be undermined by the dynamics of the socalled "prisoners' dilemma". At an individual level, everyone will probably suspect that everyone else will continue consuming and polluting without paying, and consequently will continue to do so themselves. At a national level, all governments believe that all the others will allow pollution and therefore do not create carbon markets or set carbon taxes. Practically speaking, the effects of human activity on the environment, and on our tourism activities, will thus have to be mitigated by a combination of voluntary contributions and compulsory taxes (Krugell \& Saayman, 2013). Tourism research into the mitigation of climate change has consequently focused on tourists' WTP for carbon offsets, or to contribute to a fund for the management and conservation of a particular natural resource. 


\subsection{How can we determine willingness-to-pay?}

Since no formal market exists for carbon pollution, a sustainable tourism experience or a green event, researchers have to use indirect ways to determine WTP. Three methods are used: the Travel Cost Method (TCM), the Hedonic Pricing Method (HPM) and the Contingent Valuation Method (CVM) (Van Tonder, Saayman \& Krugell, 2013). In this study, the focus falls on the last one since several authors have successfully used this method (Stern et al., 1993; Widegren, 1998; Kotchen \& Reiling, 2000; Halkos \& Matsiori, 2015).

To determine WTP, people are presented with a specific scenario on the subject of, say, climate change, and asked whether they would be willing to pay for mitigation efforts. The value that they attach to sustainability is contingent on the scenario presented and the payment is entirely hypothetical. Guidelines for this approach are outlined in the Report to the National Oceanic and Atmospheric Administration (NOAA) Panel on Contingent Valuation (CV) (Arrow et al., 1993). The CV method comprises different elements that should be considered.

The first is the scenario that is presented to the survey respondents. Such scenarios may range from national to local level, to the level of a specific site or attraction. For example, Johnson and Nemet (2010) provide a review of studies examining WTP for different policies aimed at the mitigation of climate change. In these studies the scenarios described focus on global warming and its consequences. The emphasis is on the national level and actions to be undertaken by governments. Carlson et al. (2010) also present a multi-country study based on a global warming scenario and ordinary citizens' WTP to reduce $\mathrm{CO}_{2}$ emissions. By contrast, Berk and Fovell's (1998) scenarios focus on climate change as it is experienced locally. They argue that people can more realistically be expected to consider changes in familiar micro-climates. Brouwer et al. (2008) outline the global climate change scenario, but then narrow down the willingness-to-pay aspect, to offsetting $\mathrm{CO}_{2}$ emissions caused by short- and long-haul flights. In Casey et al. (2010), the focus is very specific, and the scenario outlines the impact on a coral reef on the Mexican coast of an excessive number of visitors and describes tourists' WTP additional fees to protect the reef. The framing of the scenario is important for a number of reasons:

- The scope of the problem presented in the scenario may challenge respondents' knowledge of the topic. If the topic is global warming, people will have heard about it, but have little knowledge of the possible impact of a rise in temperature of two or four degrees Celsius. If the scenario concerns a very specific or local natural resource, people may not have heard of the issue or may consider it insignificant. Consequently, the description of the scenario is important.

- The scenario may also influence respondents' views on the coordination problem mentioned above; if the problem is too big or too complicated, some might think that it is someone else's problem and decide that since it is likely that no one else will contribute, neither will they. Again, the required global or local action explained during the survey may influence the result.

- The scenario is also linked to the proposed intervention, funded by the hypothetical payment. People may be more or less likely to be willing to pay, depending on whether they think that their hypothetical dollars, euros or rands will be well managed and spent. The manner in which this is explained in the survey has an impact on willingness to pay.

The second element to be considered is the way in which the willingness-to-pay question is asked. CV methods may employ open-ended questions, dichotomous choices, payment cards or bidding games (Anderson, 2004). Open-ended questions specifically ask respondents how much they are willing to pay for common non-market resources. Dichotomous choice methods include a single value payment that may be either accepted or rejected by respondents (Anderson, 2004). Where payment cards are used, values of hypothetical payments are printed, and respondents are asked how close the values are to the maximum amount that they are willing to pay for non-market resources. In bidding games, hypothetical payments for common resources may be stacked in ascending or descending order until the respondent rejects or accepts a value (Anderson, 2004). The way in which the willingness-to-pay question is framed determines the statistical analysis that 
is possible and whether the economic value of the environmental good in question can be inferred. The purpose of this study, however, is not to calculate the aggregate amount for WTP, but rather to shed light on who would be willing to pay by applying the CV method.

The third element is related to the framing of the willingness-to-pay question. Casey et al. (2010) refer to it as hypothetical bias and the "cheap talk" problem. Since the payment is hypothetical, the stated preference may be distorted by a "warm glow" effect - people enjoy saying that they would contribute to a good cause. The difference between the willingness-to-pay and actual behaviour becomes the cheap talk. In such a case, the willingness-to-pay measure reflects moral satisfaction and it becomes less useful as a tool for assigning monetary value to a natural resource. Researchers attempt to limit this by adding a direct explanation of this problem to their survey document.

Finally, researchers are interested not only in whether people are willing to pay, but also in who these people are. The surveys used to determine willingness-to-pay typically include a range of other questions aimed at eliciting the characteristics of the respondents. The following subsection reviews the predictors of willingness-to-pay identified in the literature.

\subsection{Who are willing to pay?}

Johnson and Nemet (2010) state in their review that "many studies seek to associate attitudinal and behavioural variables with WTP measures" (p.5). Demographic variables are used to distinguish the character of the survey samples, and the common explanatory variables used in the studies surveyed include measures of:

- environmental engagement,

- environmental attitudes/beliefs,

- education level,

- perceived efficacy of policy/strategy,

- political views,

- level of certainty of climate change and policy outcomes,

- expected future temperature/precipitation levels, and

- perceptions of others' efforts.

Krugell and Saayman (2013) examined the characteristics of athletes participating in the Two Oceans Marathon who were willing to pay for carbon off-sets. These researchers found that a greater proportion of women than men were willing to pay, which supports research by Diamantopoulos, Schlegelmilch, Sinkovics and Bohlen (2003), Jain and Kaur (2006), and Saayman and Saayman (2014), but contradicts research by Chandler (1972), Lyons and Breakwell (1994) and Meffert and Bruhn (1996), who found the opposite. Krugell and Saayman (2013) also established that more athletes with a degree or diploma or with a post-graduate qualification were willing to pay, which supports Diamantopoulos et al. (2003), Chandler (1972), Saayman and Saayman (2014), Jain and Kaur (2006), but contradicts Arbuthnot and Lingg (1975) and Schahn and Holzer (1990). The literature indicates that when it comes to age, Diamantopoulos et al. (2003), Zimmer, Strafford and Strafford (1994) and Meffert and Bruhn (1996) have demonstrated that older people are less "green". Concerning type of occupation, Krugell and Saayman (2013) have found that those who were self-employed were willing to pay more, which corroborates research by Anderson and Cunningham (1972) and Balderjahn (1988); however, most research has indicated that no significant relationship exists (Buttel \& Flinn 1978; Kruger \& Saayman 2013).

Concerning the issues related to attitudes and environmental views, Clayton and Myers (2009) discuss the motivation behind conservation psychology, which is concerned with the reasons why some people are concerned about the environment, while others are not, and why some people care about the environment. In this context Halkos and Matsiori (2015) state that knowledge of people's attitudes and views will help to predict their behaviour. Ogunbode (2013) adds that positive attitudes and behaviour lead to pro-environment behaviour. It is therefore paramount to determine first of all what the characteristics are of those who are willing to pay. Seeing that the 
number of events held is increasing globally, it is of interest to academics and practitioners alike to gain more insight into what is happening in the events and tourism sector. Only a few studies were found that examined the characteristics of atheletes who participate in sports events and who are willing to pay for carbon off-set (see Krugell \& Saayman, 2013).

\section{Description of the survey data}

To examine the characteristics of the cyclists and their WTP to offset their carbon footprint for the tour, a survey was conducted using a structured questionnaire. The questionnaire was based on earlier work by Krugell and Saayman (2013) for the Two Oceans Marathon. The questionnaire comprised four sections. Section A captured socio-demographic information such as cyclists' spending behaviour. Section B focused on the cyclists' behavioural information. Section C captured 21 motivational statements pertaining to their participation in the cycle tour on a 5-point Likert scale of importance, and Section D captured the cyclists' environmental views or attitudes based on 19 statements. They were specifically asked about their opinions on initiatives that could ensure a greener cycle tour. They rated each of the statements from $1=$ not at all important to $5=$ extremely important. The cyclists were surveyed before the race at the expo and selected on a next-to-pass basis. From a total of approximately 30000 cyclists, a sample of 400 was drawn and questionnaires were distributed to these cyclists; 371 completed questionnaires were used for the purposes of this paper.

The choice of the event and the manner in which the survey was conducted were aimed at ameliorating some of the concerns related to the willingness-to-pay analysis mentioned in the previous section. The broadest scenario of carbon emissions and global warming was used. This was selected as an issue that would be familiar to respondents, and the seriousness of it was easily driven home by mentioning that the carbon footprint of the average participant is approximately $150 \mathrm{~kg}$ of $\mathrm{CO}_{2}$, for the event. The idea of paying extra for the event to help offset the carbon footprint might have suffered from the coordination problem described above, but the questions eliciting the participants' green views were focused on specific and feasible initiatives that the organisers of the cycle tour could take. The analysis below sets out to examine the relationship between cyclists' views of initiatives where every participant can make a difference, and their WTP for a global common good. Finally, Food and Trees for Africa was chosen as the potential recipient of the hypothetical payment. This is a well-established independent organisation with a sound track record and a clear task: in this instance, to plant trees to compensate for the cyclists' contribution to climate change. At the time of the survey, the minimum amount required to purchase a tree was R20.00, which was then used in our design. We have indicated the dollar amount for the sake of foreign participants.

The first step in analysing the survey results is to describe the data. The SPSS ${ }^{\mathrm{TM}}$ statistical software package was used in the analysis. Approximately 69 per cent of the respondents in the survey were male, and 31 per cent were female. The ages of the respondents varied between 15 and 78 years, but the average age was 41 years, with a standard deviation of 13 years. The majority of these athletes were English speaking ( 58 per cent); approximately 36 per cent said that they were Afrikaans speaking, and the other 6 percent indicated that they spoke another home language. Regarding education, 20 per cent of the respondents had only a Grade 12 school qualification; approximately 42 per cent had also attained a diploma or degree, and 20 per cent held a post-graduate qualification. Seventeen percent of the athletes held a professional qualification. Their occupations match these high levels of education. The majority of the respondents (36 per cent) indicated that they held professional positions; almost 16 per cent were in management and 18 per cent were self-employed. Students ( 8 per cent), technical employees (4 per cent) and salespeople (4 per cent) also accounted for a significant part of the occupational demographics. Approximately 41 per cent of the cyclists indicated that they were local residents and were effectively "day trippers" at the cycle tour. 
To examine the issue of the environment, climate change and the cyclists' WTP for climate change mitigation, the questionnaire posed the following question:

"Would you be willing to pay R20 extra, that will be donated to Trees of Africa, as an offset for your carbon footprint?" (yes/no)

Of the 371 respondents, 68 skipped the willingness-to-pay question. Another 87 indicated that they were not willing to pay such an additional fee but 216 said that they would.

The aim of this approach is not to calculate an aggregate Rand amount for WTP, but rather to shed light on the cyclists who would be willing to pay, to identify and engage such cyclists in future efforts. Table 1 presents cross-tabulations of the willingness-to-pay groupings and the gender and age group variables.

Table 1 indicates that there is a slight gender difference in WTP for climate change mitigation. Among the men, 70 per cent indicated that they were willing to pay, whereas 30 per cent were not. In comparison, 75 per cent of the women said that they were willing to pay whereas 25 per cent said that they were not. The chi-square test is, however, not significant $(p=0.406)$, indicating that there is no clear association between gender and WTP.

Table 1 also suggests that among the different age groups, the cyclists in the age groups 15 to 30 years ( 76.8 per cent), 51 to 60 years ( 77.8 per cent) and over 60 years ( 75.0 per cent) were more likely to be willing to pay to offset carbon emissions. International studies have found that older people are more likely to be willing to pay (Johnson \& Nemet, 2010), and although this sample largely supports that finding, it is also interesting to note that there is an increased sensitivity towards the environment among the younger generation (under 30 years). The chi-square test is again not significant $(\mathrm{p}=0.306)$, indicating no clear association between the age categories and WTP.

Table 1

Cross-tabulation of WTP and gender and age groups

\begin{tabular}{|c|c|c|c|c|c|}
\hline & & & \multicolumn{2}{|c|}{ WTP } & \multirow{2}{*}{ Total $^{*}$} \\
\hline & & & Yes & No & \\
\hline \multirow{6}{*}{$\begin{array}{l}\frac{1}{0} \\
\frac{0}{0} \\
\stackrel{0}{0}\end{array}$} & \multirow{3}{*}{ Male } & Count & 142 & 60 & 202 \\
\hline & & $\%$ within gender & $70.3 \%$ & $29.7 \%$ & $100.0 \%$ \\
\hline & & $\%$ within WTP R20 extra to offset carbon footprint & $67.3 \%$ & $72.3 \%$ & $68.7 \%$ \\
\hline & \multirow{3}{*}{ Female } & Count & 69 & 23 & 92 \\
\hline & & $\%$ within gender & $75.0 \%$ & $25.0 \%$ & $100.0 \%$ \\
\hline & & $\%$ within WTP R20 extra to offset carbon footprint & $32.7 \%$ & $27.7 \%$ & $31.3 \%$ \\
\hline \multirow{15}{*}{ 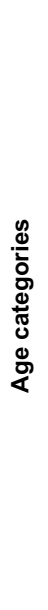 } & \multirow{3}{*}{$15-30$ years } & Count & 53 & 16 & 69 \\
\hline & & $\%$ within age categories & $76.8 \%$ & $23.2 \%$ & $100.0 \%$ \\
\hline & & $\%$ within WTP R20 extra to offset carbon footprint & $27.2 \%$ & $20.8 \%$ & $25.4 \%$ \\
\hline & \multirow{3}{*}{$31-40$ years } & Count & 43 & 26 & 69 \\
\hline & & $\%$ within age categories & $62.3 \%$ & $37.7 \%$ & $100.0 \%$ \\
\hline & & $\%$ within WTP R20 extra to offset carbon footprint & $22.1 \%$ & $33.8 \%$ & $25.4 \%$ \\
\hline & \multirow{3}{*}{$41-50$ years } & Count & 49 & 20 & 69 \\
\hline & & $\%$ within age categories & $71.0 \%$ & $29.0 \%$ & $100.0 \%$ \\
\hline & & $\%$ within WTP R20 extra to offset carbon footprint & $25.1 \%$ & $26.0 \%$ & $25.4 \%$ \\
\hline & \multirow{3}{*}{$51-60$ years } & Count & 35 & 10 & 45 \\
\hline & & $\%$ within age categories & $77.8 \%$ & $22.2 \%$ & $100.0 \%$ \\
\hline & & $\%$ within WTP R20 extra to offset carbon footprint & $17.9 \%$ & $13.0 \%$ & $16.5 \%$ \\
\hline & \multirow{3}{*}{$\begin{array}{l}61 \text { years and } \\
\text { older }\end{array}$} & Count & 15 & 5 & 20 \\
\hline & & $\%$ within age categories & $75.0 \%$ & $25.0 \%$ & $100.0 \%$ \\
\hline & & $\%$ within WTP R20 extra to offset carbon footprint & $7.7 \%$ & $6.5 \%$ & $7.4 \%$ \\
\hline
\end{tabular}

*Note: The numbers do not always add up to 303, since some respondents failed to complete certain questions Source: Compiled by authors from survey data 
Table 2 displays a cross-tabulation of the WTP for climate change mitigation with marital status and home language. A larger percentage of cyclists who were single, living together, widowed or divorced said that they were willing to pay, compared to those who were married. Interestingly, the two widows/widowers in the sample both indicated WTP.

Very little difference in WTP was found between the two predominant language groups, namely English speakers and Afrikaans speaker. However, only 52.6 per cent of those who speak "other" languages are willing to pay to offset carbon emissions. The chi-square statistic was insignificant $(\mathrm{p}=0.158)$, indicating no clear relationship between home language and WTP. The test was also performed to determine if there are differences between foreigners' and South Africans' WTP, but the result was again insignificant $(\mathrm{p}=0.517)$, indicating no clear difference in behaviour.

Table 2

Cross-tabulation of WTP and marital status and language groups

\begin{tabular}{|c|c|c|c|c|c|}
\hline & & & \multicolumn{2}{|c|}{ Willing to pay? } & \multirow{2}{*}{ Total $^{*}$} \\
\hline & & & Yes & No & \\
\hline \multirow{18}{*}{ 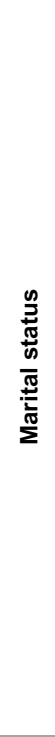 } & \multirow{3}{*}{ Married } & Count & $116_{a}$ & $566_{a}$ & 172 \\
\hline & & $\%$ within marital status & $67.4 \%$ & $32.6 \%$ & $100.0 \%$ \\
\hline & & $\%$ within WTP R20 extra to offset carbon footprint & $54.0 \%$ & $64.4 \%$ & $57.0 \%$ \\
\hline & \multirow{3}{*}{ Not married } & Count & $53 a$ & $19_{a}$ & 72 \\
\hline & & $\%$ within marital status & $73.6 \%$ & $26.4 \%$ & $100.0 \%$ \\
\hline & & $\%$ within WTP R20 extra to offset carbon footprint & $24.7 \%$ & $21.8 \%$ & $23.8 \%$ \\
\hline & \multirow{3}{*}{ In a relationship } & Count & 20 a & $7_{\mathrm{a}}$ & 27 \\
\hline & & $\%$ within marital status & $74.1 \%$ & $25.9 \%$ & $100.0 \%$ \\
\hline & & $\%$ within WTP R20 extra to offset carbon footprint & $9.3 \%$ & $8.0 \%$ & $8.9 \%$ \\
\hline & \multirow{3}{*}{ Divorced } & Count & $13 a$ & $3 a$ & 16 \\
\hline & & $\%$ within marital status & $81.3 \%$ & $18.8 \%$ & $100.0 \%$ \\
\hline & & $\%$ within WTP R20 extra to offset carbon footprint & $6.0 \%$ & $3.4 \%$ & $5.3 \%$ \\
\hline & \multirow{3}{*}{ Widow/er } & Count & $2 \mathrm{a}$ & $0_{a}$ & 2 \\
\hline & & $\%$ within marital status & $100.0 \%$ & $0.0 \%$ & $100.0 \%$ \\
\hline & & $\%$ within WTP R20 extra to offset carbon footprint & $.9 \%$ & $0.0 \%$ & $.7 \%$ \\
\hline & \multirow{3}{*}{ Living together } & Count & $11 \mathrm{a}$ & $2 \mathrm{a}$ & 13 \\
\hline & & $\%$ within marital status & $84.6 \%$ & $15.4 \%$ & $100.0 \%$ \\
\hline & & $\%$ within WTP R20 extra to offset carbon footprint & $5.1 \%$ & $2.3 \%$ & $4.3 \%$ \\
\hline \multirow{9}{*}{ 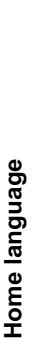 } & \multirow{3}{*}{ Afrikaans } & Count & $77_{\mathrm{a}}$ & $32 \mathrm{a}$ & 109 \\
\hline & & $\%$ within home language & $70.6 \%$ & $29.4 \%$ & $100.0 \%$ \\
\hline & & $\%$ within WTP R20 extra to offset carbon footprint & $35.8 \%$ & $36.8 \%$ & $36.1 \%$ \\
\hline & \multirow{3}{*}{ English } & Count & $128_{a}$ & $46_{a}$ & 174 \\
\hline & & $\%$ within home language & $73.6 \%$ & $26.4 \%$ & $100.0 \%$ \\
\hline & & $\%$ within WTP R20 extra to offset carbon footprint & $59.5 \%$ & $52.9 \%$ & $57.6 \%$ \\
\hline & \multirow{3}{*}{ Other } & Count & $10_{a}$ & $9_{\mathrm{a}}$ & 19 \\
\hline & & $\%$ within home language & $52.6 \%$ & $47.4 \%$ & $100.0 \%$ \\
\hline & & $\%$ within WTP R20 extra to offset carbon footprint & $4.7 \%$ & $10.3 \%$ & $6.3 \%$ \\
\hline
\end{tabular}

*Note: The numbers do not always add up to 303, since some respondents failed to complete certain questions; subscript letters denote a subset of the WTP categories whose column proportions do not differ significantly from each other at the $5 \%$ level Source: Compiled by authors from survey data

The review by Johnson and Nemet (2010) reports that education levels have been found to be a significant determinant of willingness-to-pay for mitigation change. Table 3 displays the crosstabulation of WTP and education levels and shows that the categories of cyclists with a diploma or degree (68.0 per cent) contain very similar proportions of respondents who said they were willing to pay to the categories of respondents with a post-graduate qualification (70.5 per cent) and those with a professional qualification (67.3 per cent). Interestingly, of the respondents whose highest 
qualification is a Grade 12 certificate, a much larger percentage ( 81.7 per cent) said they would be willing to pay.

Table 3

Cross-tabulation of WTP and level of education

\begin{tabular}{|c|c|c|c|c|c|}
\hline & & & \multicolumn{2}{|c|}{ Willing to pay? } & \multirow{2}{*}{ Total $^{*}$} \\
\hline & & & Yes & No & \\
\hline \multirow{20}{*}{ 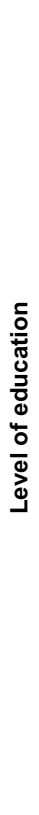 } & \multirow[t]{4}{*}{ Matric } & Count & $49_{a}$ & $11_{b}$ & 60 \\
\hline & & $\%$ within level of education & $81.7 \%$ & $18.3 \%$ & $100.0 \%$ \\
\hline & & $\%$ within WTP R20 extra to offset carbon footprint & $23.1 \%$ & $12.9 \%$ & $20.2 \%$ \\
\hline & & $\%$ of Total & $16.5 \%$ & $3.7 \%$ & $20.2 \%$ \\
\hline & \multirow[t]{4}{*}{ Diploma/Degree } & Count & $85 a$ & $40_{a}$ & 125 \\
\hline & & $\%$ within level of education & $68.0 \%$ & $32.0 \%$ & $100.0 \%$ \\
\hline & & $\%$ within WTP R20 extra to offset carbon footprint & $40.1 \%$ & $47.1 \%$ & $42.1 \%$ \\
\hline & & $\%$ of Total & $28.6 \%$ & $13.5 \%$ & $42.1 \%$ \\
\hline & \multirow[t]{4}{*}{ Post-graduate } & Count & $43 a$ & $18 \mathrm{a}$ & 61 \\
\hline & & $\%$ within level of education & $70.5 \%$ & $29.5 \%$ & $100.0 \%$ \\
\hline & & $\%$ within WTP R20 extra to offset carbon footprint & $20.3 \%$ & $21.2 \%$ & $20.5 \%$ \\
\hline & & $\%$ of total & $14.5 \%$ & $6.1 \%$ & $20.5 \%$ \\
\hline & \multirow[t]{4}{*}{ Professional } & Count & $33_{a}$ & $16_{a}$ & 49 \\
\hline & & $\%$ within level of education & $67.3 \%$ & $32.7 \%$ & $100.0 \%$ \\
\hline & & $\%$ within WTP R20 extra to offset carbon footprint & $15.6 \%$ & $18.8 \%$ & $16.5 \%$ \\
\hline & & $\%$ of total & $11.1 \%$ & $5.4 \%$ & $16.5 \%$ \\
\hline & \multirow[t]{4}{*}{ Other } & Count & $2 \mathrm{a}$ & $0_{a}$ & 2 \\
\hline & & $\%$ within level of education & $100.0 \%$ & $0.0 \%$ & $100.0 \%$ \\
\hline & & $\%$ within WTP R20 extra to offset carbon footprint & $.9 \%$ & $0.0 \%$ & $.7 \%$ \\
\hline & & $\%$ of total & $.7 \%$ & $0.0 \%$ & $.7 \%$ \\
\hline
\end{tabular}

*Note: The numbers do not always add up to 303, since some respondents failed to complete certain questions; subscript letters denote a subset of the WTP categories whose column proportions do not differ significantly from each other at the $5 \%$ level Source: Compiled by the authors from survey data

A cross-tabulation of WTP and the different occupational groups does not reveal substantial differences. Greater proportions of the professionals, managers, administrators and self-employed individuals said they would be willing to pay to offset their carbon footprint, whereas those in education and technical occupations indicated lower WTP. Similar to the findings of the survey by Krugell and Saayman (2013) undertaken at the Two Oceans Marathon, the respondents who are self-employed were again more inclined (72.2 per cent) to make a contribution, although those in management were even more likely to do so (76.6 per cent). In a number of occupational categories, the numbers of respondents are too small to form the basis for workable conclusions.

Finally, it is also possible to examine the cyclists' total spending and relate it to their stated WTP and observe that some differences exist. The average total spending of those who said they were willing to pay was R4 631, whereas for those who said they were not willing to pay it was R3 474. However, an analysis of variance indicates that this difference is not significant $(p=0.112)$.

Building on this description, the following section presents the empirical analysis of the predictors of which cyclists said they would be willing to pay more for a sustainable event.

\section{Results}

\subsection{Principal component analysis}

A description of demographic variables helps to characterise a sample, and the above analysis shows interesting differences between the respondents who said they were willing to pay and those 
that were not. The literature review further identified that personal beliefs and attitudes play an important role in WTP for the environment.

This is the first study in the South African context on WTP for green initiatives, and therefore exploratory methods were used in the analysis. More specifically, the number of statements (19) was reduced using exploratory factor analysis, where principal components were extracted using Promax rotation. The results from the principal component analysis of these views were used to characterise each type of cyclist and link them to their stated WTP.

The Anderson-Rubin method was used for the calculation of factor scores, to obtain standard normal scores. The Kaiser-Meyer-Olkin (KMO) measure of sampling adequacy was 0.927 and Bartlett's test of sphericity was significant $(\mathrm{p}<0.001)$, which indicates that principle component analysis may be used for this data set. In total, three factors were identified with Eigen values greater than one, and they explain 68.47 percent of the variance of the data. Table 4 documents the classification from the rotated component matrix and Table 5 records the classification of cyclists by their views on what would ensure a greener cycle tour.

Table 4

Types of cyclists by their green views

\begin{tabular}{|l|c|c|c|}
\hline & \multicolumn{2}{|c|}{ Component } \\
\cline { 2 - 4 } & $\mathbf{2}$ & $\mathbf{2}$ \\
\hline Cyclists retaining their own litter, disposing of it after the race & 0.542 & & \\
\hline Opportunity to be part of the Ride for Nature with WWF-SA & 0.882 & & \\
\hline Providing information on your carbon footprint at the cycle tour & 0.943 & & \\
\hline Providing opportunity to buy carbon credits & 0.907 & & \\
\hline Providing opportunity to financially support other green initiatives at the race & 0.799 & & \\
\hline Recognition of clubs or teams that support a greener race & 0.610 & & \\
\hline Recycling bins at the expo & & 0.934 & \\
\hline Recycling bins along the route & & 0.878 & \\
\hline Visible signage regarding recycling methods and bins along the route & & 0.724 & \\
\hline Recycling of paper, bottle and cans etc. during and after the race & & 0.770 & \\
\hline Providing information regarding current recycling activities by cycle tour & & 0.678 & \\
\hline Providing information regarding current recycling methods for cyclists & & 0.606 & \\
\hline Stronger awareness of the "stash your trash" initiative & & & 0.644 \\
\hline Marketing material and forms to be printed on recycled paper & & & 0.571 \\
\hline The use of energy-saving lights at the expo & & & 0.696 \\
\hline Providing the opportunity to buy bio-degradable products at the expo & & & 0.624 \\
\hline The use of local products and produce by food vendors & & & 0.715 \\
\hline Environmentally friendly packaging of food & & & 0.797 \\
\hline Cycle tour's support for a particular conservation agency & & & 0.642 \\
\hline Mean value & 3.54 & 4.03 & 4.00 \\
\hline Cronbach's alpha & 0.89 & 0.90 & 0.75 \\
\hline Soure: Compled by the athos from surve & & \\
\hline
\end{tabular}

Source: Compiled by the authors from survey data

The first factor represents the cyclists who feel that more information about aspects such as the carbon footprint and recycling is important. They want to get involved and feel that the opportunity to buy carbon credits or to financially support green initiatives will help to ensure a greener cycle tour. The factor mean score is 3.54 and the Cronbach's alpha is 0.89 .

The recyclers are represented by the second factor. They focused on recycling as the key to a greener cycle tour. The mean score for this factor is 4.03 and the Cronbach's alpha, 0.90 .

The third factor groups together responses that indicate the importance of a broader view of a green cycle tour. These cyclists want more local food products in environmentally friendly packaging, bio-degradable products and material on recycled paper as well as energy saving at the expo. The mean score of all the items in this factor is 4.00 and the Cronbach's alpha, 0.75 . 
Table 5

Types of cyclists by their green views

\begin{tabular}{|c|c|c|}
\hline Green money & Re-"cyclers" & Green products \\
\hline $\begin{array}{l}\text { - Cyclists retaining their own litter, } \\
\text { disposing of it after race } \\
\text { - Opportunity to be part of Ride for } \\
\text { Nature with WWF-SA } \\
\text { - Providing opportunity to buy carbon } \\
\text { credits } \\
\text { - Providing information on carbon } \\
\text { footprint at the cycle tour } \\
\text { - Providing opportunity to financially } \\
\text { support other green initiatives at the } \\
\text { race } \\
\text { Recognition of clubs or teams that } \\
\text { support a greener cycle tour }\end{array}$ & $\begin{array}{l}\text { - } \quad \text { Recycling bins at the expo } \\
\text { - } \quad \text { Recycling bins along the route } \\
\text { Visible signage for bins along the } \\
\text { route } \\
\text { - } \quad \text { Recycling of paper, bottles, cans } \\
\text { before, during and after the race } \\
\text { - } \quad \begin{array}{l}\text { Providing information regarding } \\
\text { current recycling activities }\end{array} \\
\text { - Providing information regarding } \\
\text { recycling methods for cyclists }\end{array}$ & $\begin{array}{l}\text { - Use of local products and produce by } \\
\text { - Eood vendors } \\
\text { - Environmentally friendly packaging of } \\
\text { - Use of energy-saving lights at the } \\
\text { expo } \\
\text { - Cycle tour supporting a particular } \\
\text { conservation organisation } \\
\text { - Providing opportunity to buy bio- } \\
\text { - degradable products at the expo } \\
\text { - Stronger awareness of "stash your } \\
\text { - Marketinitiative } \\
\text { recycled paper }\end{array}$ \\
\hline
\end{tabular}

Source: Compiled by the authors.

To explore in greater detail whether there are clear distinctions between green views and WTP, the respondents were classified according to their most prominent view; the following table compares the socio-demographic characteristics of the various groups. It is noteworthy that 56.7 per cent of all respondents fall into the re-"cyclers" category, while only 9.1 per cent could be classified as "green money" and 34.2 per cent as "green products".

Table 6

Characteristics of cyclists by their green views

\begin{tabular}{|l|l|l|l|}
\hline \multicolumn{1}{|c|}{ Characteristic } & \multicolumn{1}{c|}{ Green money } & \multicolumn{1}{c|}{ Re-“cyclers” } & \multicolumn{1}{c|}{ Green products } \\
\hline $\begin{array}{l}\text { Gender } \\
\text { Age }\end{array}$ & $52.6 \%$ female & $67.8 \%$ male & $67.6 \%$ male \\
Marital status & 40.2 years & 40.8 years & 43.1 years \\
Home language & $57.9 \%$ married & $55.1 \%$ married & $60.6 \%$ married \\
& $47.4 \%$ English; & $58.5 \%$ English; & $53.5 \%$ English; \\
Level of education & $42.1 \%$ Afrikaans & $33.9 \%$ Afrikaans & $43.7 \%$ Afrikaans \\
& $42.1 \%$ Diploma/Degree; & $35.6 \%$ Diploma/Degree; & $56.3 \%$ Diploma/Degree; \\
& $32.1 \%$ Post-graduate/ & $39.0 \%$ Post-graduate/ & $25.4 \%$ Post-graduate/ \\
& Professional & Professional & $57.7 \%$ \\
\hline Willing to pay & $57.9 \%$ & $67.2 \%$ & \\
\hline
\end{tabular}

Those cyclists who could be classified as "green money" are predominantly female, with an average age of just over 40 years. They are mainly married and hold some form of post-school qualification. Interestingly, only 57.9 per cent of them indicated that they were willing to pay to offset their carbon footprint due to the event. "Re-cyclers" are predominantly male cyclists, also just over 40 years of age, and mainly English-speaking. Most of them hold some form of postschool qualification and 67.2 per cent are willing to pay to offset their carbon footprint. The cyclists classified under "green products" are also predominantly male, but slightly older (43.1 years), married and English-speaking. This group contains the highest number of respondents who hold a post-school qualification (81.7 per cent), and 57.7 per cent of these cyclists indicated that they were willing to pay to offset their carbon footprint.

\subsection{Logistic regression analysis}

To determine how these green views are related to willingness-to-pay to offset their carbon footprints, a binary logistic regression model was estimated using EViews 8 and STATA 12. In its simplest form, the model may be written as:

$$
P(Y)=\frac{1}{1+e^{-\left(b_{0}+b_{1} X_{1}+b_{2} X_{2}+\cdots+b_{n} X_{n}+\epsilon_{i}\right)}}
$$

$P(Y)$ is the probability of $Y$ occurring; in this case, the probability that the cyclists would say that they were willing to pay to offset their carbon footprint, given known values of the $X$ 's. For this part of the analysis the respondents who indicated that they would be willing to make a 
contribution are contrasted: firstly, with those who were not willing to pay and secondly, with both those who were not willing to pay and those who did not complete the questions. Failure to complete the willingness-to-pay questions can also be viewed as a protest response, since it is associated with some form of protest against the stated scenario (Meyerhoff \& Liebe, 2006). The treatment of those who do not complete the question is contentious, since the respondent has not made a clear choice. However, since it is often viewed as an indication of non-agreement, the protest response can be thought of as a "no" to the WTP question.

The predictors included in the model are:

- Gender, where female is the comparator category (MALE).

- Age, which is treated as a continuous variable (AGE). Since the cross-tabulation indicated that there might be a non-linear relationship between age and WTP, the square of age was also included to account for these non-linearities $\left(\mathrm{AGE}^{\wedge} 2\right)$.

- Education, which is a scale variable, where 1 indicates lower levels of education and 5 indicates higher levels of education (EDU).

- Total spending of the respondent due to the Argus Cycle Tour (SPEND).

- The main three occupation categories were also included (OCCU1 = professionals; OCCU2 = managers; OCCU3 = self-employed).

- Green views (based on the components extracted above).

Two approaches were again followed, with the last variable being green views: Firstly, the factor scores were included in the analysis (FACTOR1, FACTOR2, FACTOR3), and secondly, based on the individual factor scores, respondents were classified as belonging to one of these groups (RECYCLERS, GREEN PRODUCTS, GREEN MONEY) indicated in Table 6 above. "Green money" was chosen as the comparator group, since it received the lowest overall mean score of all three components extracted. With the classification system used, a respondent who leans more towards "green money" than towards any of the other categories will only be classified as "green money" (i.e. a dichotomous variable that takes the value of 1 in GREEN MONEY and 0 in both the other categories). However, it is true that a person who would like to buy carbon credits and who would like to support other green initiatives financially (i.e. GREEN MONEY), would also be keen to recycle (although slightly less). With the classification system, this is not taken into account. With the factor scores system, the scores take all the respondent's information into consideration and the respondent would therefore have a score for both "GREEN MONEY" and "RECYCLING", although the latter would be lower. Because the factors and classifications depend on one another, they are used separately in the analysis to avoid encountering problems associated with multicollinearity.

The results of the first part of the analysis are recorded in Table 7 below. In this analysis, those who indicated that they were willing to pay are contrasted with those who indicated clearly that they were not (i.e. non-respondents were left out of the analysis). Both the approaches outlined above to control for respondents' green views were included and are shown in the table.

From the table it is evident that age, education, occupation 2 (managers) and factor 2 (recyclers) are predictors of WTP, with age bearing a non-linear relationship, as expected. Interestingly, education is robustly negatively associated with willingness-to-pay, while managers are more likely to be willing to pay. To facilitate interpretation, the odds ratio is added, with odds greater than 1 indicating that there is a positive association, and those less than 1 indicating a negative association.

Based on the information criteria and R-squared values, the models are very comparable, although the model which includes the factors is slightly better than the one which includes the classification of respondents according to their green views. 
Table 7

Results of the logistic regression analysis (1st part)

\begin{tabular}{|c|c|c|c|c|c|c|c|c|}
\hline Variable & Coefficient & Odds ratio & Std error & Prob. & Coefficient & Odds ratio & Std error & Prob. \\
\hline C & 8.174 & 3549.1 & 2.817 & 0.004 & 4.794 & 120.8 & 2.031 & 0.018 \\
\hline AGE & -0.316 & 0.729 & 0.137 & 0.022 & -0.143 & 0.866 & 0.098 & 0.144 \\
\hline $\mathrm{AGE}^{\wedge} 2$ & 0.004 & 1.004 & 0.002 & 0.013 & 0.002 & 1.002 & 0.001 & 0.083 \\
\hline SPEND & 0.000 & 1.000 & 0.000 & 0.907 & 0.000 & 1.000 & 0.000 & 0.720 \\
\hline EDU & -0.511 & 0.600 & 0.245 & 0.037 & -0.670 & 0.512 & 0.218 & 0.002 \\
\hline MALE & -0.674 & 0.510 & 0.542 & 0.214 & -0.716 & 0.489 & 0.487 & 0.141 \\
\hline OCCU1 & 0.577 & 1.781 & 0.611 & 0.345 & 0.482 & 1.619 & 0.569 & 0.397 \\
\hline OCCU2 & 2.373 & 10.728 & 1.203 & 0.049 & 2.391 & 10.922 & 1.195 & 0.046 \\
\hline OCCU3 & 1.000 & 2.717 & 0.677 & 0.140 & 0.981 & 2.667 & 0.637 & 0.124 \\
\hline FACTOR1 & -0.225 & 0.799 & 0.443 & 0.612 & & & & \\
\hline FACTOR2 & 0.682 & 1.978 & 0.285 & 0.017 & & & & \\
\hline FACTOR3 & -0.256 & 0.774 & 0.373 & 0.492 & & & & \\
\hline RECYCLER & & & & & 0.805 & 2.238 & 0.501 & 0.108 \\
\hline PRODUCTS & & & & & 0.503 & 1.654 & 0.569 & 0.377 \\
\hline \multicolumn{3}{|c|}{ McFadden R-squared } & \multicolumn{2}{|c|}{0.171} & \multicolumn{2}{|c|}{ McFadden R-squared } & \multicolumn{2}{|c|}{0.142} \\
\hline \multicolumn{3}{|c|}{ Akaike info criterion } & \multicolumn{2}{|c|}{1.201} & \multicolumn{2}{|c|}{ Akaike info criterion } & \multicolumn{2}{|c|}{1.221} \\
\hline \multicolumn{3}{|c|}{ Schwarz criterion } & \multicolumn{2}{|c|}{1.490} & \multicolumn{2}{|c|}{ Schwarz criterion } & \multicolumn{2}{|c|}{1.459} \\
\hline \multicolumn{3}{|l|}{ LR statistic } & \multicolumn{2}{|c|}{$22.986^{* *}$} & \multicolumn{2}{|l|}{ LR statistic } & \multicolumn{2}{|c|}{$23.393^{* *}$} \\
\hline \multicolumn{3}{|c|}{ Restr. log likelihood } & \multicolumn{2}{|c|}{-67.341} & \multicolumn{2}{|c|}{ Restr. log likelihood } & \multicolumn{2}{|c|}{-82.522} \\
\hline \multicolumn{3}{|c|}{ Avg. log likelihood } & \multicolumn{2}{|c|}{-0.494} & \multicolumn{2}{|c|}{ Avg. log likelihood } & \multicolumn{2}{|c|}{-0.529} \\
\hline \multicolumn{3}{|l|}{$F(11,102)$} & \multicolumn{2}{|c|}{$1.67^{*}$} & \multicolumn{2}{|l|}{$F(10,124)$} & \multicolumn{2}{|c|}{$1.77^{\star}$} \\
\hline
\end{tabular}

Source: Compiled by authors from estimations

Table 8 displays the results of the second analysis: it compares those who were willing to pay with those who indicated that they were not as well as those who did not complete the question. For both sets of green views included in the analysis, the results are again comparable. In both regression models, age, education level, occupation 2 (managers) and 3 (self-employed) are predictors of WTP. The green view variables are significant in the second model (where respondents are classified according to their views), but not in the first, where the principal components were added as explanatory variables.

From the models estimated, the following findings are evident: Firstly, age is a non-linear predictor of WTP to offset $\mathrm{CO}_{2}$ emissions and the relationship is consistent and significant in all the models. This result partially supports research by Diamantopoulos et al. (2003), Saayman and Saayman (2014) and Meffert and Bruhn (1996), who found young people to be more willing to pay for greener events. This implies that future research should try to understand the reasons why some cyclists are not willing to pay, especially those in the middle-aged group.

Secondly, there is a negative relationship between education levels and cyclists who are willing to pay for the environment. This finding contradicts research by Krugell and Saayman (2013) and also indicates that, compared to marathon runners, it seems that the variables influencing willingness-to-pay differ from one sporting event to the next. This implies that the variables that influence such willingness seem to be event- or sport-type specific, which means that each type of event should develop its own strategy.

Thirdly, gender and total spending (i.e. ability to pay) are not significant in any of the estimated models. This supports research by Kruger and Saayman (2013), Diamantopoulos et al. (2003) and Samdahl and Robertson (1989), implying that the strategy for this particular event can be similar for both males and females.

Fourthly, people in management positions as well as those who are self-employed are more likely to be willing to pay for the environment. This result supports research by Krugell and 
Saayman (2013), Anderson and Cunningham (1972) and Balderjahn (1988). The reason is most probably that these categories have the financial means to pay.

Table 8

Results of the logistic regression analysis (2nd part)

\begin{tabular}{|c|c|c|c|c|c|c|c|c|}
\hline Variable & Coefficient & Odds ratio & Std. error & Prob. & Coefficient & Odds ratio & Std. error & Prob. \\
\hline C & 5.942 & 380.6 & 1.814 & 0.001 & 5.728 & 307.3 & 1.927 & 0.003 \\
\hline AGE & -0.217 & 0.805 & 0.082 & 0.008 & -0.234 & 0.791 & 0.088 & 0.008 \\
\hline $\mathrm{AGE}^{\wedge} 2$ & 0.002 & 1.002 & 0.001 & 0.007 & 0.003 & 1.003 & 0.001 & 0.005 \\
\hline SPEND & 0.000 & 1.000 & 0.000 & 0.106 & 0.000 & 1.000 & 0.000 & 0.342 \\
\hline EDU & -0.589 & 0.555 & 0.185 & 0.001 & -0.616 & 0.540 & 0.192 & 0.001 \\
\hline MALE & -0.376 & 0.686 & 0.380 & 0.323 & -0.650 & 0.522 & 0.412 & 0.115 \\
\hline OCCU1 & 0.807 & 2.241 & 0.477 & 0.091 & 0.838 & 2.311 & 0.538 & 0.120 \\
\hline OCCU2 & 1.822 & 6.183 & 0.697 & 0.009 & 2.221 & 9.220 & 0.752 & 0.003 \\
\hline OCCU3 & 1.256 & 3.510 & 0.509 & 0.014 & 1.241 & 3.459 & 0.566 & 0.028 \\
\hline FACTOR1 & -0.138 & 0.872 & 0.309 & 0.656 & & & & \\
\hline FACTOR2 & 0.353 & 0.890 & 0.221 & 0.110 & & & & \\
\hline FACTOR3 & -0.116 & 1.423 & 0.298 & 0.697 & & & & \\
\hline RECYCLERS & & & & & 1.542 & 4.676 & 0.432 & 0.000 \\
\hline PRODUCTS & & & & & 1.380 & 3.974 & 0.500 & 0.006 \\
\hline \multicolumn{3}{|c|}{ McFadden R-squared } & \multicolumn{2}{|c|}{0.122} & \multicolumn{2}{|c|}{ McFadden R-squared } & \multicolumn{2}{|c|}{0.183} \\
\hline \multicolumn{3}{|c|}{ Akaike info criterion } & \multicolumn{2}{|c|}{1.349} & \multicolumn{2}{|c|}{ Akaike info criterion } & \multicolumn{2}{|c|}{1.253} \\
\hline \multicolumn{3}{|c|}{ Schwarz criterion } & \multicolumn{2}{|c|}{1.574} & \multicolumn{2}{|c|}{ Schwarz criterion } & \multicolumn{2}{|c|}{1.459} \\
\hline \multicolumn{3}{|l|}{ LR statistic } & \multicolumn{2}{|c|}{$27.69^{\star *}$} & \multicolumn{2}{|l|}{ LR statistic } & \multicolumn{2}{|c|}{$41.67^{\star \star}$} \\
\hline \multicolumn{3}{|c|}{ Restr. log likelihood } & \multicolumn{2}{|c|}{-113.9} & \multicolumn{2}{|c|}{ Restr. log likelihood } & \multicolumn{2}{|c|}{-113.85} \\
\hline \multicolumn{3}{|c|}{ Avg. log likelihood } & \multicolumn{2}{|c|}{-0.602} & \multicolumn{2}{|c|}{ Avg. log likelihood } & \multicolumn{2}{|c|}{-0.560} \\
\hline \multicolumn{3}{|l|}{$F(11,155)$} & \multicolumn{2}{|c|}{$2.01^{* *}$} & \multicolumn{2}{|l|}{$F(10,156)$} & \multicolumn{2}{|c|}{$2.78^{\star *}$} \\
\hline
\end{tabular}

Source: Compiled by authors from estimations

In terms of cyclists' views on the environment, those who score high on factor 2 (re-cyclists) are more likely to contribute to the environment. This result is also quite robust, with "re-cyclists" spending more than those who hold "green money" views, in all the regressions. When a dummy variable is added for "green products", it is also significant, indicating a positive association with stated WTP to offset their carbon footprint compared to "green money". It therefore appears that there should be a distinct focus on recycling as the first step in managing a green event.

In summary, the data reveal that demographic variables, most notably age, occupation and education as well as the right attitude towards the environment, are significant predictors of stated WTP for climate change mitigation. Based on this, the question arising is: What are the recommendations for the organisers of the event and researchers who are interested in conducting research in this field.

Practical advice for tourism service providers or event organisers who want to make their offerings more environmentally friendly and persuade participants to pay for this is that they will need to target their initiatives. Old and young cyclists who are in management positions or selfemployed will be part of their market, but they also need to identify their green-minded consumers. It may not only be about finding them, but also about developing them. Surveys and promotions may be used to try to identify green-minded consumers. They could be asked about their green views, or green behaviour at home, in a survey. Promotions might take the form of a voucher where consumers can choose between spending the money on themselves or spending it on a green project. To develop their green consumers, venues or events could raise awareness of the environmental impact of visitors' behaviour. Providing more information about mitigation efforts, such as planting trees or recycling, goes some way towards influencing people's green views. 


\section{Conclusions}

The aim of this paper was to make a contribution to the literature by extending the explanatory variables used to explain willingness-to-pay for environmental initiatives; in this case, offsetting the carbon footprint of cyclists taking part in the Cape Argus Pick n Pay Cycle Tour. The key finding is that specific types of green views or typology are positively and significantly associated with stated WTP. This research has made a clear contribution to the literature on green events and, specifically, sport events. It has also added types (typology) of green cyclists, which is an addition to and improvement on the earlier research undertaken by Krugell and Saayman (2013). The variables that influence WTP, compared to other sports events, are also different, implying that these results differ from one sports event to the next.

The research also has certain limitations, the most noteworthy of which is that it does not probe the reasons why certain respondents are not willing to pay. This is an area that needs additional research. Furthermore, this research takes a dualistic view, not only regarding the inclusion of green views but also regarding its treatment of the protest response. The first analysis only included those respondents who indicated a clear "no" in the stated willingness- to-pay question, while the second analysis also included the non-responses as a protest response and therefore a "no". This adds robustness to the analysis, but again the protest response could benefit from further explanation in future research.

Further research in this field needs to examine the range of explanatory variables of WTP. It would also be possible to refine the measures of people's green views, depending on the context, but in addition researchers should consider trying to measure other influences, such as perceived efficacy of interventions, or the role of perceptions of others' efforts.

\section{Acknowledgements:}

This work is based on research supported in part by the National Research Foundation of South Africa. The grantholders acknowledge that opinions, findings and conclusions or recommendations in any publication generated by the NRF supported research are that of the authors, and that the NRF accepts no liability whatsoever in this regard.

The authors would also like to thank the anonymous reviewers for their valuable comments as well as the respondents who completed the questionnaires diligently.

\section{References}

ANDERSON, D.A. 2004. Environmental economics and natural resources management. Mason, $\mathrm{OH}$ : Thomson South-Western.

ANDERSON, W.T. \& CUNNINGHAM, W.H. 1972. The socially conscious consumer. Journal of Marketing, 36(3):23-31.

ARBUTHNOT, J. \& LINGG, S. 1975. A comparison of French and American environmental behaviours. International Journal of Psychology, 10(4):275-81.

ARROW, K., SOLOW, R., PORTNEY, P., LEAMER, E., RADNER, R. \& SCHUMAN, H. 1993. Report of the NOAA panel on contingent valuation. Federal Register, 58(10):4602-4614.

BALDERJAHN, I. 1988. Personality variables and environmental attitudes as predictors of ecologically responsible consumption patterns. Journal of Business Research, 17(1):51-6.

BERK, R.A. \& FOVELL, R.G. 1998. Public perceptions of climate change: A "willingness to pay" assessment. Climate Change, 41:413-446.

BLACK, P.A., CALITZ, E. \& STEENKAMP, T.J. 2010. Public economics $\left(4^{\text {th }}\right.$ ed. $)$ Cape Town: Oxford University Press.

BROUWER, R., BRANDER, L. \& VAN BEUKERING, P. 2008. A convenient truth: Air travel passengers willingness to pay to offset their $\mathrm{CO}_{2}$ emissions. Climatic Change, 90:299-313.

BUTTEL, F.H. \& FLINN, W.L. 1978. The politics of environmental concern: The impact of party identification and political ideology on environmental attitudes. Environment and Behavior, 10(1):17-37. 
CARLSON, F., KATARIA, M., KRUPNICK, A., LAMPI, E., LOFGREN, A., QIN, P., CHUNG, S. \& STERNER, T. 2010. Paying for mitigation: A multiple country study. Environment and Development, Discussion Paper Series, EfD DP:10-12.

CASEY, J.F., BROWN, C.B. \& SCHMANN, P. 2010. Are tourists willing to pay additional fees to protect corals in Mexico? Journal of Sustainable Tourism, 18(4):557-573.

CHANDLER, R. 1972. Public opinion: Changing attitudes and contemporary political and social issues. New York: Bowker.

CLAYTON, S. \& MYERS, S. 2009. Conservation psychology: Understanding and promoting human care for nature. Hoboken, NJ: Wiley-Blackwell.

DIAMANTOPOULOS, A., SCHLEGELMILCH, B.B., SINKOVICS, R.R. \& BOHLEN, G.M. 2003. Can socio-demographics still play a role in profiling green consumers? A review of the evidence and an empirical investigation. Journal of Business Research, 56(1): 465-80.

FISHER, J. 2007. Current issues in the interdisciplinary field of climate change and tourism: A meta-study of articles from 2006 and 2007. Paper presented at the European Tourism and the Environment Conference: Promotion and Protection, Achieving the Balance. Dublin, Ireland, 11-12 September.

FOOD AND TREES FOR AFRICA. 2013. Carbon calculator. Available at: http://www.trees.co.za/carbonoffset/carbon-calculator.html [accessed June 2013].

HALKOS, G. \& MATSIORI, S. 2015. Environmental attitude, motivations and values for marine biodiversity protection. No. 63947.University Library of Munich, Germany.

JAIN, S.K. \& KAUR, G. 2006. Role of socio-demographics in segmenting and profiling green consumers: An exploratory study of consumers in India. Journal of International Consumer Marketing, 18(3):107-46.

JOHNSON, E. \& NEMET, G. 2010. Willingness to pay for climate policy: A review of the estimates. Working paper series 011 , University of Wisconsin-Madison.

KOTCHEN, M. J. \& REILING, S. D. 2000. Environmental attitudes, motivations, and contingent valuation of nonuse values: A case study involving endangered species. Ecological Economics, 32(1):93-107.

KRUGELL, W.F. \& SAAYMAN, M. 2013. Running the green race: Willingness-to-pay evidence from the Two Oceans Marathon 2011. South African Journal for Research in Sport, Physical Education and Recreation, 35(1):53-70.

KRUGER, M. \& SAAYMAN, M. 2013. How green are visitors at a green wine destination in South Africa? Acta Academia, 45(3):63-98.

LYONS, E. \& BREAKWELL, G.M. 1994. Factors predicting environmental concern and indifference in 13to 16-year-olds. Environment and Behaviour, 26(2):223-38.

MEFFERT, H. \& BRUHN, M. 1996. Das umwelbewußtsein von konsuneneten. Die Betriebswirtch, 56(5):621-58.

MEYERHOFF, J. \& LIEBE, U. 2006. Protest beliefs in contingent valuation: Explaining their motivation. Ecological Economics, 57:583-594.

OGUNBODE, C.A. 2013. The NEP scale: Measuring ecological attitudes/worldviews in an African context. Environment, Development and Sustainability, 15(6):1477-1494.

SAAYMAN, M., KRUGELL, W.F. \& SAAYMAN, A. 2016. Willingness to pay: Who are the cheap talkers? Annals of Tourism Research, 56:96-111.

SAAYMAN, M. \& SAAYMAN A. 2014. Who is willing to pay to see the Big 7? Tourism Economics, 20(6):1181-1198.

SAMDAHL, D.M. \& ROBERTSON, R. 1989. Social determinants of environmental concern: Specification and test of the model. Environment and Behaviour, 21(1):57-81.

SCHAHN, J. \& HOLZER, E. 1990. Studies of individual environmental concern: The role of knowledge, gender and background variables. Environment and Behaviour, 22(6):767-86.

STERN, P.C., DIETZ, T. \& KALOF, L. 1993, Value orientations, gender, and socio-psychological context. Environment and Behaviour, 27:723-743.

VAN TONDER, C. 2013. Determining tourists' valuation of the Big Five. Master's dissertation, North-West University, Potchefstroom.

VAN TONDER, C., SAAYMAN, M. \& KRUGELL, W. 2013. Tourists' characteristics and willingness to pay to see the Big Five. Journal of Economic and Financial Sciences, 6(3):631-644. 
WIDEGREN, O. 1998.The new environmental paradigm and personal norms. Environment and Behaviour, 30(1):75-100.

ZIMMER, M.R., STRAFFORD, T.F. \& STRAFFORD, M.R. 1994. Green issues: Dimensions of environmental concern. Journal of Business Research, 30(1):63-74. 